\title{
Flow Visualization at Cryogenic Conditions Using a Modified Pressure Sensitive Paint Approach
}

\author{
A. Neal Watkins", William K. Goad”. Clifford J. Obara ${ }^{\ddagger}$. Danny R. Sprinkle , Richard L. Campbell ${ }^{* *}$. \\ Melissa B. Carter ${ }^{+\neq}$, and Odis C. Pendergraft. Jr. \\ NASA Langley Research Center. Hampton, Virginia, 23681, USA \\ James H. Bell ${ }^{\mathrm{s}}$ \\ NASA Ames Research Center, Moffett Field, California, 94035, USA \\ JoAnne L. Ingram ${ }^{* * *}$ and Donald M. Oglesby ${ }^{4+\dagger}$ \\ Swales Aerospace, Inc., Hampton, Virginia, 23681. USA
}

and

Pamela J. Underwood $d^{++\neq}$and Linda R. Humber

Jacobs Sverdnip, Hampton, Virginia, 23681. USA

\begin{abstract}
A modification to the Pressure Sensitive Paint (PSP) method was used to visualize streamlines on a Blended Wing Body (BWB) model at full-scale flight Reynolds numbers. In order to achieve these conditions, the tests were carried out in the National Transonic Facility operating under cryogenic conditions in a nitrogen environment. Oxygen is required for conventional PSP measurements, and several tests have been successfully completed in nitrogen environments by injecting small amounts (typically $<3000 \mathrm{ppm}$ ) of oxygen into the flow. A similar technique was employed here, except that air was purged through pressure tap orifices already existent on the model surface, resulting in changes in the PSP wherever oxygen was present. The results agree quite well with predicted results obtained through computational fluid dynamics analysis (CFD), which show this to be a viable technique for visualizing flows without resorting to more invasive procedures such as oil flow or minitufts.
\end{abstract}

$\begin{array}{ll} & \\ A, B & =\text { PSP calibration coefficients with arbitrary pressure reference } \\ M & =\text { Mach number } \\ P & =\text { Pressure }\end{array}$

\footnotetext{
*Electronics Engineer, Advanced Sensing and Optical Measurement Branch. Mail Stop 493

Engineering Technician, Advanced Sensing and Optical Measurement Branch. Mail Stop 236

Electronics Engineer, Experimental Research Services Leadership, Mail Stop 237. AIAA Member

Electronics Engineer, Center Operations Directorate, Mail Stop 413

** Senior Research Engineer. Configuration Aerodynamics Branch, Mail Stop 499. AlAA Associate Fellow

Aerospace Engineer, Configuration Aerodynamics Branch, Mail Stop 499. AIAA Member

Aerospace Engineer, Configuration Aerodynamics Branch, Mail Stop 499, AIAA Senior Member

Aerospace Engineer, Mail Stop 260-1, AIAA Member

${ }^{* * *}$ Research Chemist. NASA Langley Research Center, Mail Stop 493

Research Chemist. NASA Langley Research Center, Mail Stop 493

Research Engineer, NASA Langley Research Center, Mail Stop 267

Instrumentation Technician, NASA Langley Research Center, Mail Stop 267
}

This material is declared a work of the U.S. Government and is not subject to copyright protection in the United States.

1 


$\begin{array}{ll}K_{S !} & =\text { Stern-Volmer constant } \\ I & =\text { Intensity of light emitted by PSP } \\ \alpha & =\text { Angle of Attack } \\ \text { CFD } & =\text { Computational Fluid Dynamics } \\ \text { PSP } & =\text { Pressure sensitive paint } \\ \text { TSP } & =\text { Temperature Sensitive Paint } \\ \text { UV } & =\text { Ultraviolet } \\ \text { LED } & =\text { Light Emitting Diode } \\ \text { BLI } & =\text { Boundary Layer Ingestion } \\ \text { kPa } & =\text { kilopascal } \\ \text { BWB } & =\text { Blended Wing Body } \\ \text { NTF } & =\text { National Transonic Facility } \\ \text { Pt(TfPP) } & =\text { platinum meso-tetra(pentafluorophenyl) porphine } \\ \text { FIB } & =\text { fluoroisobutylmethacrylate co-polymer } \\ \text { PTMSP } & =\text { polytrimethylsilylpropyne }\end{array}$

\section{Introduction}

A modification of the Pressure Sensitive Paint (PSP) technique was used to visualize changes in flow characteristics around different nacelle configurations on a Blended Wing Body (BWB) model at full-scale flight Reynolds numbers. This test was conducted at the National Transonic Facility (NTF) at NASA Langley Research Center in Hampton, Virginia, and full-scale flight Reynolds numbers were achieved at cryogenic conditions. Because of the pristine conditions required for operation at cryogenic conditions, no tunnel seeding or introduction of any type of liquid is permissible. Thus, flow visualization techniques have been limited to fluorescent minitufts and focusing Schlieren, both of which do not address the need to determine flows in small regions of the model without changing the aerodynamics. Because of this, a modified PSP technique was used to visualize flow in these areas.

PSP and TSP allow for the accurate determination of pressure and temperature distributions over an aerodynamic surface and are based on an emitted optical signal from a luminescent coating. As originally developed, ${ }^{1-3}$ this technique was primarily useful for mean pressure measurements in high speed flows, but has since been adapted to low speed flows ${ }^{4-6}$ as well as measurements of fluctuating pressures. ${ }^{7.8}$ A number of review articles cover the topic in detail. ${ }^{9-11}$ PSP measurements exploit the oxygen $\left(\mathrm{O}_{2}\right)$ sensitivity of luminescent probe molecules suspended in gas-permeable binder materials. In wind tunnel applications, the PSP (or TSP) is applied to the model by conventional paint spraying techniques. Light sources such as UV LED arrays are mounted external to the test section to illuminate the painted model and effect luminescence emission from the entrapped oxygen-sensitive molecules. For the majority of pressure paints, PSP emission occurs in the red or orange region of the visible spectrum $(\sim 580-650 \mathrm{~nm})$. The intensity is inversely proportional to the amount of oxygen present such, that brighter regions in the paint emission indicate lower concentration of oxygen relative to the darker regions. Scientific-grade CCD cameras with spectral band-pass filters to discriminate between the excitation (blue) and emission (orange) signals, capture the intensity image of the PSP-coated model surface, providing a means to recover global surface pressure distributions on test articles of interest. PSP measurement systems all employ a ratio of image pairs to compensate for intensity non-uniformity due to sources other than oxygen concentration, the most significant of which are paint application and illumination heterogeneity. In the conventional approach, PSP images acquired either prior to or immediately following tunnel operation (wind-off) are ratioed with images acquired at each tunnel condition (wind-on).

If the test surface under study is immersed in an atmosphere containing $\mathrm{O}_{2}$ (e.g. air), the recovered luminescence intensity can be described by the Stern-Volmer relationship ${ }^{12}$

$$
\frac{I_{0}}{I}=1+K_{S V} P_{O_{2}}
$$

where $I_{0}$ is the luminescence intensity in the absence of $\mathrm{O}_{2}$ (i.e. vacuum), $I$ is the luminescence intensity at some partial pressure of oxygen $P_{O_{2}}$, and $K_{S V}$ is the Stern-Volmer constant. The value of $K_{S V}$ depends on the properties of both the luminescent molecules and the binder, and is generally temperature dependent. Since it is a practical 
impossibility to measure $I_{1}$ in a wind tunnel application. a modified form of the Stem-Volmer equation is typically used. This form replaces the vacuum calibration ( $\left.l_{h}\right)$ with a reference standard

$$
\frac{I_{R E F}}{l}=A+B \frac{P}{P_{R E F}}
$$

where $I_{R E F}$ is the recovered luminescence intensity at a reference pressure. $P_{R E F} . A$ and $B$ are temperature dependent constants for a given PSP formulation and are usually determined before hand using laboratory calibration procedures.

PSP measurements are difficult to make under cryogenic conditions for two reasons. First. the test gas is typically nitrogen, refrigerant, or some other medium which typically contains little or no oxygen. Second. the diffusion of oxygen into the paint binder is highly temperature dependent. and at low temperatures, is practically nonexistent. As such. it is not surprising that initial cryogenic testing with luminescent paints used TSP. Successful cryogenic PSP measurements have been conducted at The NASA Langley 0.3-Meter Transonic Cryogenic Tunnel ${ }^{1.4}$ as well as other facilities ${ }^{15}$ using a PSP binder that has a very large diffusion rate and bleeding in known amounts of oxygen into the flow stream.

For visualization of the streamlines on the BWB model. a modification of this technique was employed. similar to a method suggested by Peterson and Fitzgerald. Instead of injecting known concentrations of oxygen into the wind stream, air was purged from existing pressure port orifices on the model surface, causing a decrease in the luminescence of the PSP. As the pressure ports are in distinct locations, and the ejected air interacts only with areas closest to the ports, this will give an indication of flow in these regions. Tests were carried out at the NASA Ames Research Center before the BWB test in order to verify the efficacy of this technique as well as to determine the magnitude of purging pressures required. These results as well as the results from the BWB model will be discussed.

\section{Experimental}

\section{A. PSP Formulations}

All PSP formulations used in the current study consisted of dissolving an oxygen sensitive luminophore. $\mathrm{Pt}(\mathrm{TfPP})$, in an oxygen-permeable binder. For the verification tests at NASA Ames, which was conducted at room temperature, the oxygen-permeable binder is a FIB co-polymer developed at the Lniversity of Washington ${ }^{17}$ and commercially available from Innovative Scientific Solutions. Inc. (ISSI)." This binder was chosen due to its high oxygen sensitivity and low temperature sensitivity. ${ }^{1-18}$ During the BWB test at the NTF. the oxygen permeable binder used was PTMSP. ${ }^{14.15}$ chosen because it is a glassy polymer with a large free volume and having a low diffusion barrier to oxygen. leading to high oxygen permeability even at cryogenic conditions.

\section{B. Verification Test at NASA Ames}

Verification tests for this modified PSP technique were conducted in two small tunnels at the NASA Ames Research Center. The PSP research wind tunne $\mathrm{I}^{20}$ is a small closed return wind tunnel. with the test section arranged vertically above the drive fan. The drive fan is powered by a $75 \mathrm{~kW}$ electric motor. which is located within the fan housing. The motor/fan unit rests on flexible mounts which isolate it from the rest of the wind tunnel structure to minimize vibration. The tunnel itself is built of fiberglass with a metal frame. A radiator installed upstream of the contraction section circulates refrigerated water to cool the flow. The PSP tunnel can be operated up to speeds of $120 \mathrm{~m} / \mathrm{s}(\mathrm{M}=0.35)$.

The test section measures $30.5 \mathrm{~cm} \times 30.5 \mathrm{~cm} \times 61 \mathrm{~cm}$. The sidewalls are made of UV-transparent plexiglass. while the top and bottom walls are aluminum. The top and bottom walls have cutouts for model-mounting hardware. All non-transparent parts of the test section are painted flat black to reduce extraneous reflections.

The PSP tunnel is fairly well sealed while running. and as a result can be operated with nitrogen as the tunnel working fluid. The tunnel has two valves, one in the settling chamber upstream of the contraction section. and one in the diffuser upstream of the drive fan, which can be opened to mix in outside gasses. Nitrogen operation was accomplished by connecting the diffuser valve to a nitrogen gas cylinder. while opening the contraction section valve. The contraction section sees higher than atmospheric pressure, and so gas escapes from the tunnel. By

\footnotetext{
*http: www.innssi.com
} 


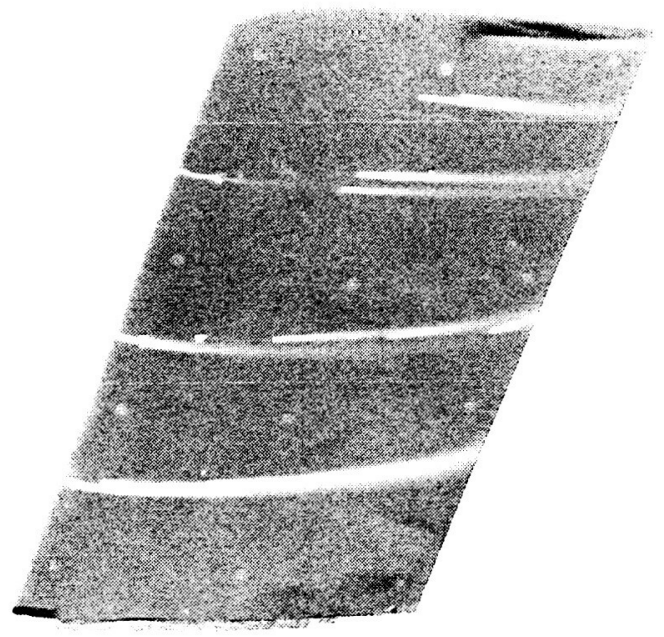

Figure 2. Resulting image from ratioing the purge-on image from Fig. 1 (a) to the purge-off image from Fig. 1 (b) showing the increased contrast of the streamlines caused by nitrogen interacting with the PSP on the model.

of air purge the streaks are dimmer. (And the overall brightness of the model is higher since it is operating in a lower oxygen environment.)

Initial testing at low speeds with nitrogen purge into air was carried out in the PSP tunnel. This was followed by tests using air purge into nitrogen. A comparison of images taken with the two techniques showed no difference in terms of the ability to visualize streamlines. Therefore all further testing was accomplished using nitrogen purge into air, since data at different speeds and different purge pressures could be obtained much more easily with this gas combination. Figure 1 depicts a typical image collected with nitrogen blowing through the ports and one without nitrogen at $\alpha=5^{\circ}$ and $M=0.55$. While the streamlines can be visualized when the nitrogen is being purged out of the ports (lighter "streaks" on the surface), the contrast is very poor. This result was seen irregardless of tunnel speed $(\mathrm{M}=0.1$ to 0.55$)$ or nitrogen purge pressure $(27.6 \mathrm{kPa}$ (gauge) to $276 \mathrm{kPa}$ (gauge) ).

As detailed above, standard PSP measurements are conducted by ratioing a reference image with a run image (wind-off/wind-on). A slight modification of this procedure was applied to this data in order to increase the contrast for visualizing the effects of nitrogen on the surface. First, an image was taken without nitrogen purging through the ports ("purge-off"). Next, an image was taken with the nitrogen purge on ("purge-on"). The final step in data reduction is to ratio the purge-on image with the purge-off image, resulting in the image shown in Fig. 2 . The contrast of the streamlines on the surface of the model is greatly improved, and it is readily apparent that the nitrogen remains attached to the surface over a large amount of chord. Several of the orifices on the model surface were clogged from previous testing; therefore nitrogen is only able to be purged out of relatively few ports (approximately 13). Furthermore, the manifold used in these experiments does not provide an even flow of nitrogen to the ports, resulting in some nitrogen traces that are more distinct than others.

The verification test was also used to determine both the optimum pressure of the purge gas as well as the effects of tunnel speed on this pressure. The results, shown in Fig. 3, show that when the purging pressure is only slightly above the pressure in the tunnel $(27.6-82.7 \mathrm{kPa}$ (gauge)), there is little effect on the nitrogen interaction with the surface. Furthermore, tunnel speed shows very little effect on the optimal purge pressure as well. However, when large purge pressures are employed, a significant degradation in the ability to visualize surface flows becomes apparent. As seen in Fig. 4, when purge pressures of 138 and $276 \mathrm{kPa}$ (gauge) are used, the streamlines appear much broader and less distinct, especially at larger distances from the orifice. This suggests that the nitrogen jets are strong enough to penetrate the boundary layer, where they are convected downstream without affecting the $\mathrm{O}_{2}$ concentration at the surface.

\section{B. BWB Test at NTF}

In order to transition this technique to the NTF wind tunnel operating at cryogenic conditions in a nitrogen environment, a different PSP formulation needed to be employed. The formulation chosen was based on PTMSP, a polymer known to have high oxygen permeability, even at low temperatures. A typical response curve of 200 ppm 


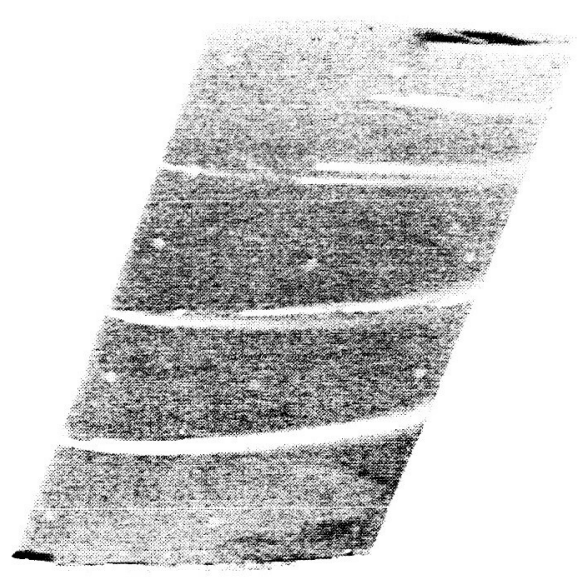

a),

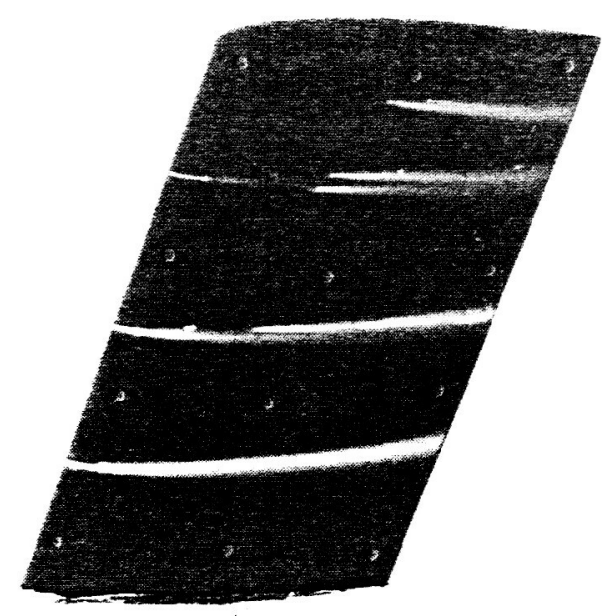

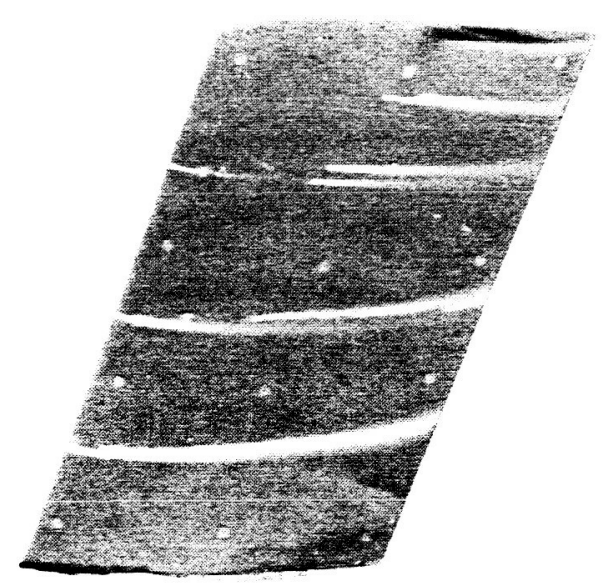

b),

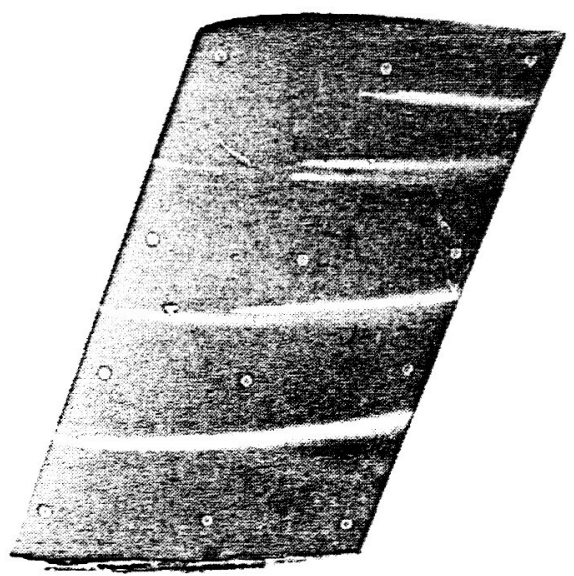

d),

Figure 3. Effect of purge pressure and speed on the streamlines observed when nitrogen is purged through the ports. All images are ratios of purge-on to purge-off. a) $M=0.55,27.6 \mathrm{kPa}$ (gauge) purge pressure; b) $\mathrm{M}=0.55,82.7 \mathrm{kPa}$ (gauge) purge pressure; c) $\mathrm{M}=0.3,27.6 \mathrm{kPa}$ (gauge) purge pressure; d) $\mathbf{M}=0.3,82.7 \mathrm{kPa}$ (gauge) purge pressure.

$\mathrm{Pt}(\mathrm{TfPP})$ in PTMSP at $-150^{\circ} \mathrm{C}$ in an environment of $2000 \mathrm{ppm}$ oxygen in nitrogen is shown in Fig. 5. These data show that even at low temperature, the PTMSP binder has sufficient oxygen permeability to allow small oxygen concentrations to significantly quench the $\operatorname{Pt}(\mathrm{TfPP})$.

A data acquisition procedure similar to that used in the verification tests was also used to acquire flow visualization images on the BWB model in the NTF. However, since oxygen was purged into a nitrogen environment, the streamlines would appear as dark streaks instead of lighter streaks. Because of this, data analysis was accomplished by taking a ratio of the purge-off image to the purge-on image.

Figure 6 shows image ratios collected at room temperature (before the cool-down procedure began) at different tunnel speeds. These images were collected as a final verification of the technique as well as determining the expected change in signal with the introduction of air through the pressure ports. At the higher speeds $(\mathrm{M}=0.85)$, a shock across the surface of the model is readily apparent. This is also illustrated by taking a plot of the pixel values across the shock location, as shown in Fig. 7. This shock visualization is most likely not due to a change in pressure, as the oxygen ejected through the ports will not have had time to dissipate across the model as is shown in Fig. 6 . It is believed that this is due to a refractive index change caused by the shock itself, similar to data collected using Schlieren techniques.

These images show many interesting results, especially just forward and around the nacelle regions as shown in Figure 8 . The nitrogen streamlines show that flow is very steady until just forward of the nacelles. In this region, the flow seems to choke (the streamlines become significantly shorter) just before it curves around the nacelle. 


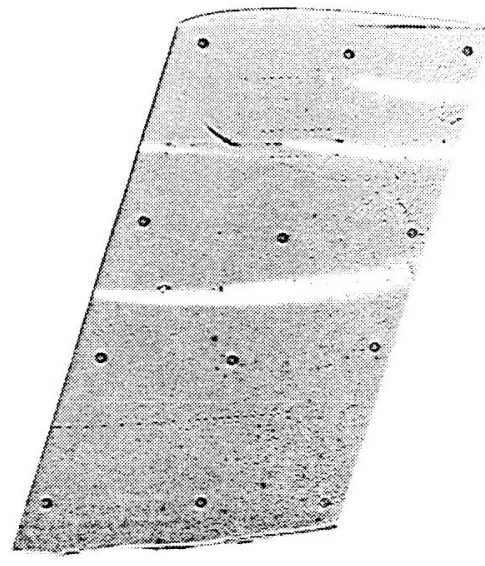

a),

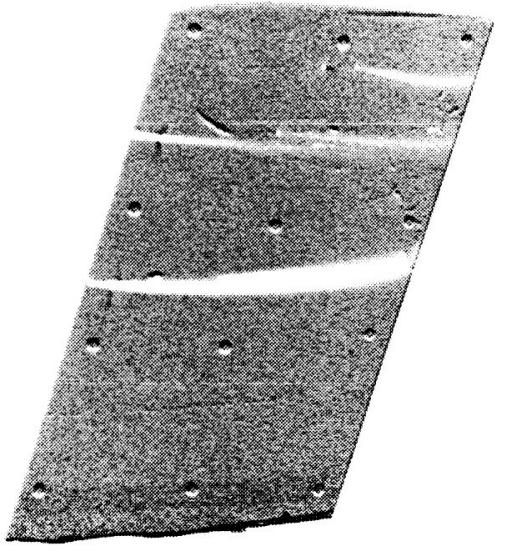

b),

Figure 4. Effect of higher purge pressure on nitrogen streamlines. All images are ratios of purge-on to purgeoff. a) $\mathrm{M}=0.2,138 \mathrm{kPa}$ (gauge) purge pressure; b) $\mathrm{M}=0.2,276 \mathrm{kPa}$ (gauge) purge pressure.

Furthermore, there seems to be evidence that the flow begins to reverse in the nacelle itself as it becomes completely choked.

The cool-down procedure for the NTF afforded ample opportunities to determine optimum data acquisition procedures, including purge pressures. Similar to the verification test, the best results were obtained when the purge pressure was limited to slightly above the tunnel pressure. It was also determined that a slight leak was present in an access hatch in the model. The effects of this leak with increasing purge pressure are shown in Fig. 9.

With many of the data acquisition and analysis procedures determined during the verification test and the cool-down process in the NTF, data were then acquired at full flight Reynolds numbers. These flight conditions were achieved by cooling the tunnel to $-156{ }^{\circ} \mathrm{C}$ and running at a speed of $\mathrm{M}$ $=0.85$. Typical image ratios for a specific model configuration at angles of attack of $3^{\circ}, 4^{\circ}$, and $5^{\circ}$ are shown in Fig. 10. It should be noted that these images were collected using a secondary camera as the primary camera suffered a malfunction just prior to data collection.

From these images, the shock location is readily apparent and its location as a function of $\alpha$

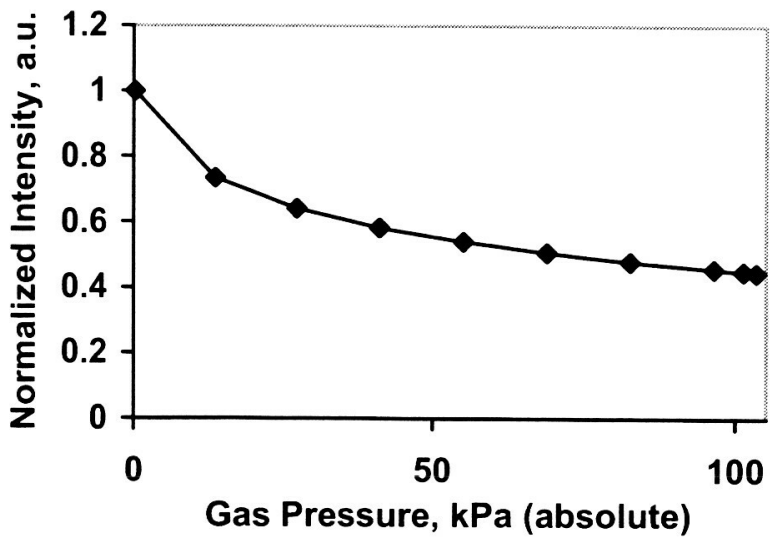

Figure 5. Typical intensity response curve of $200 \mathrm{ppm}$ Pt(TfPP) in PTMSP to increasing gas pressure. The gas used was $2000 \mathrm{ppm}$ oxygen in nitrogen and data was collected at $-150^{\circ} \mathrm{C}$. can be monitored. At the lowest $\alpha$ value $\left(3^{\circ}\right)$, the shock is forward of the viewing location. However at $4^{\circ}$ and $5^{\circ} \alpha$ values, the shock location is clearly moving to the aft portion of the body. The resolution of the streamlines on the body itself has also suffered at the low temperatures used at these conditions. This is a result of the high purge pressures required (tunnel pressure was $\sim 262 \mathrm{kPa}$ (absolute), resulting in a purge pressure of $\sim 310 \mathrm{kPa}$ (absolute)) and orifice blocking caused by water freezing in the lines. The sodium sulfate filter was not adequate to reduce the water so that the dew point was below the tunnel operating temperature. Furthermore, several small portions of the PSP coating were removed due to the extreme cold and high velocity of the tunnel. The regions of the paint that were removed occurred only in regions where a model change had just occurred (in this case, the flaps were changed to a different configuration). In all cases of paint removal, the entire paint coating (PSP and basecoat) was removed. This effect has been encountered previously, ${ }^{21}$ and for future tests, all model pieces will be painted separately or (if not practical) painting will not occur over seams that would be broken during model changes. 


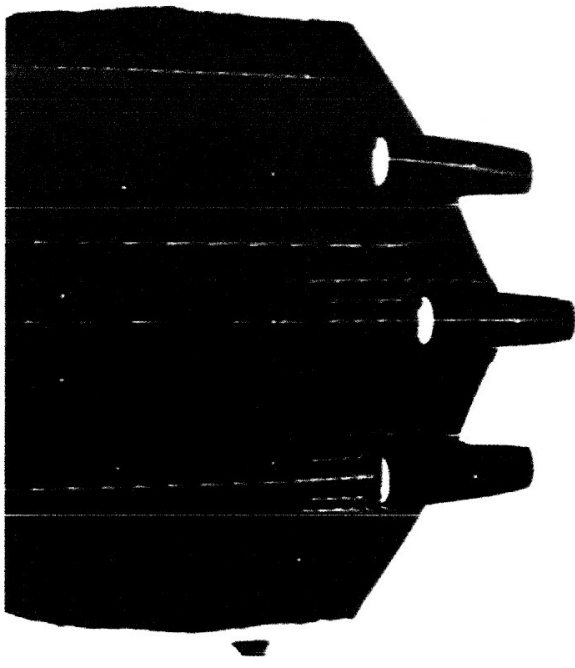

a),

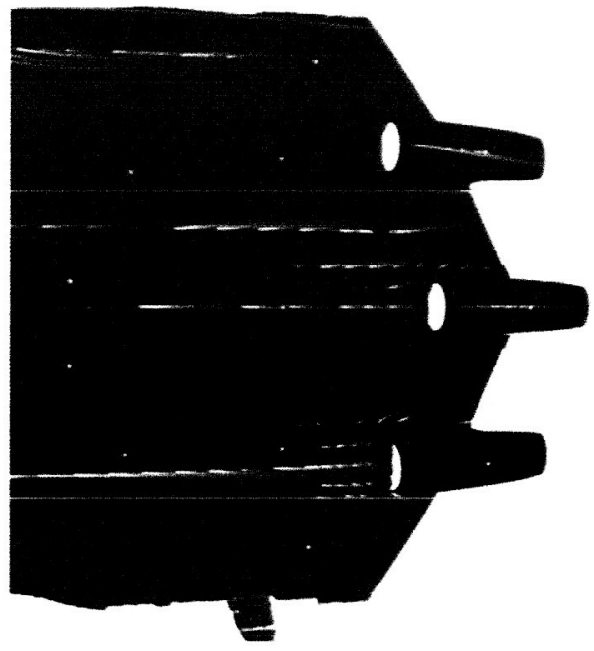

b),

Figure 6. Ratioed images of purge-off to purge-on for BWB model. Data was collected at room temperature $\left(-24^{\circ} \mathrm{C}\right)$ at $\alpha=4^{\circ}$. a) $M=0.2$; b) $M=0.85$.
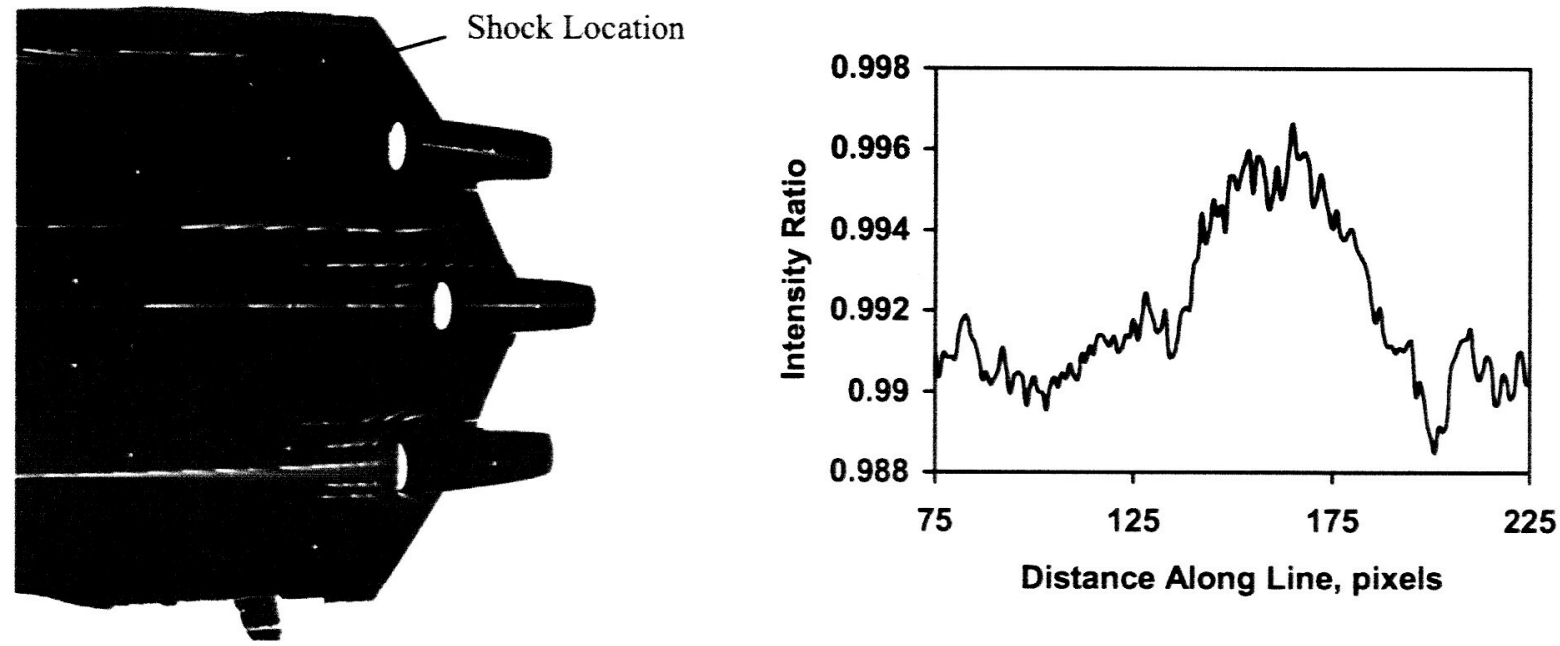

Figure 7. Ratioed image showing the visualization of the shock location on the surface of the model. Data was collected at room temperature with $M=0.85$ and $\alpha=4^{\circ}$. The inset shows the pixel intensity variation across the shock location defined by the line in the image.

\section{Comparison with CFD Results}

The experimental results were compared with computational fluid dynamics solutions. As described in Ref. 22 , the USM3D flow solver ${ }^{23}$ coupled with the CDISC design method ${ }^{24}$ was used in the analysis and design of the BWB model. The USM3D code solves the Reynolds-averaged Navier-Stokes equations using a Roe upwind scheme on unstructured meshes. For the BWB design, a wall function option with the Spalart-Allmaras turbulence model was used to reduce the number of grid points required to resolve the boundary layer. The semi-span grid for the BWB with boundary-layer ingestion (BLI) nacelles contained about 4 million tetrahedral cells.

A sample comparison of the CFD results with the PSP flow visualization for the redesigned BLI configuration with the central flaperons deflected 5 degrees is shown in Fig. 11. Before addressing the results in the figure, two differences between the CFD and PSP cases should be noted. The first is that the flaperon deflection was modeled in the CFD by simply distorting the original wing grid, so that there are no gaps or vertical surfaces at the stream-wise 


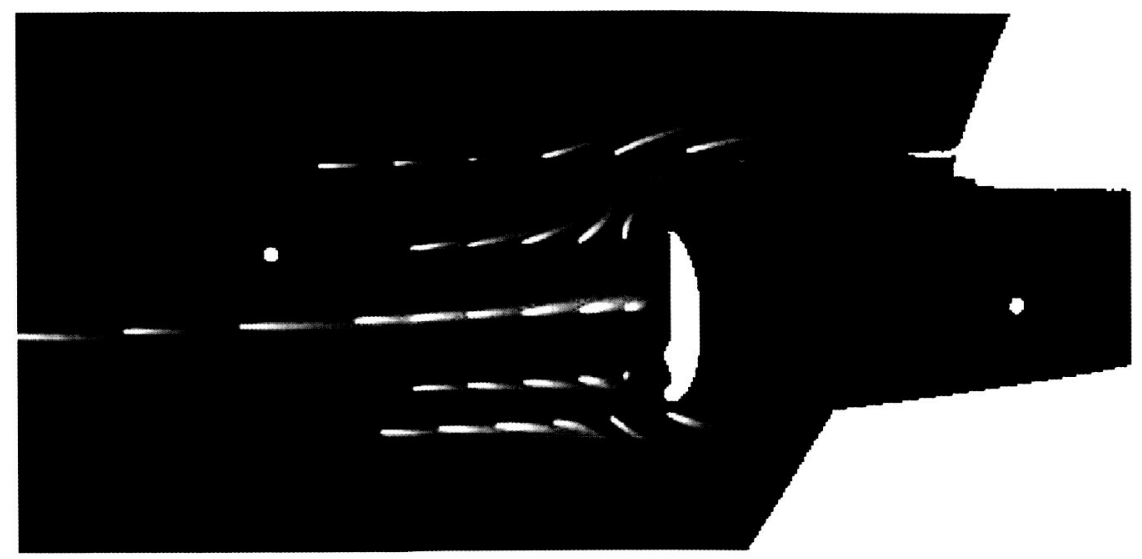

Figure 8. Enhanced view of streamline behavior near the nacelles. Image collected at room temperature, $\alpha=4^{\circ}$, and $M=0.85$. The streamlines appear shorter near the inlet of the nacelle due to choking of the flow, subsequently causing the flow to divert around the nacelle.

edges of the control surfaces. Second, although flow visualization data were acquired at the CFD conditions of Mach number of 0.85 , angle of attack of about $4^{\circ}$, and Reynolds number of $75 \times 10^{6}$ (based on the mean aerodynamic chord), the PSP images obtained at warmer temperatures were much clearer. Since they were still at a fairly high Reynolds numbers $\left(20 \times 10^{6}\right)$ and the flow should thus be very similar to that at the CFD conditions, one of these images was selected for the figure.

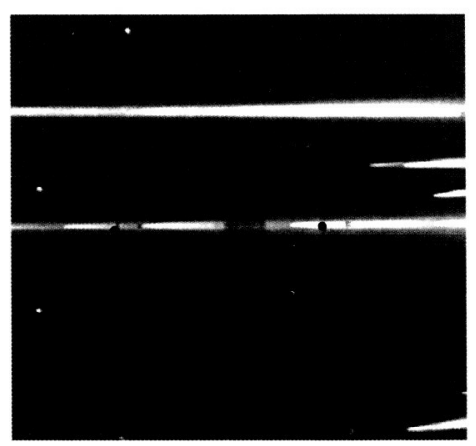

a),
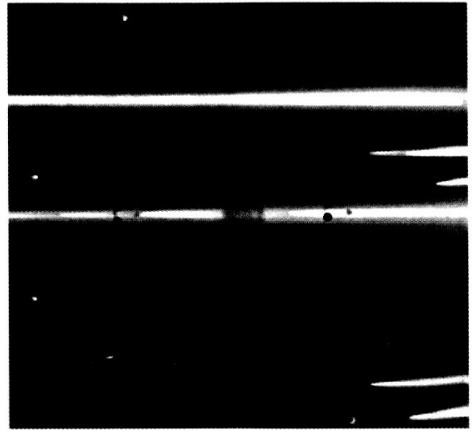

b),

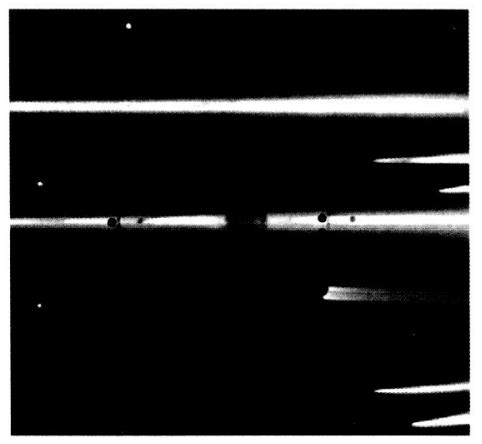

c),

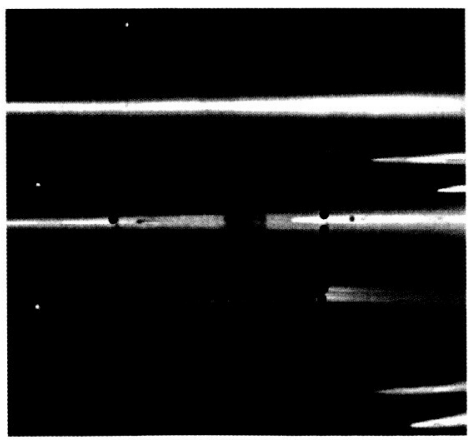

e),

Figure 9. Air leakage as a function of purge pressure through an access panel on the top of the BWB model. All images acquired at $M=0.12$. a) $179 \mathrm{kPa}$ (absolute) purge pressure; b) $214 \mathrm{kPa}$ (absolute) purge pressure; c) $275 \mathrm{kPa}$ (absolute) purge pressure; d) $317 \mathrm{kPa}$ (absolute) purge pressure; and e) $351 \mathrm{kPa}$ (absolute) purge pressure. The access hatch is outlined in each image. 


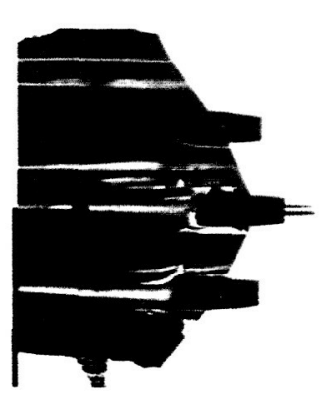

a),

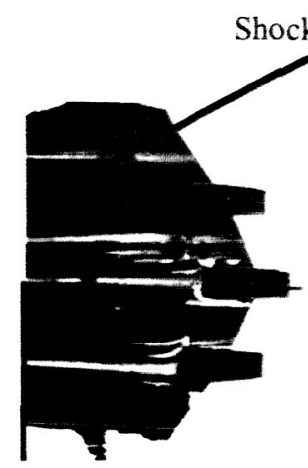

b),

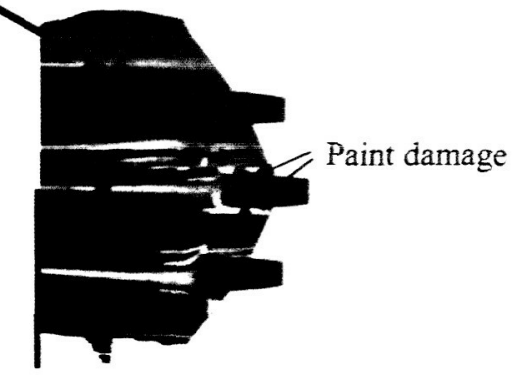

c),

Figure 10. Ratioed images showing streamlines as a function of $\alpha$ at $-156^{\circ} \mathrm{C}$ and $\mathrm{M}=0.85$. a) $\alpha=3^{\circ}$; b) $\alpha=4^{\circ}$; and c) $\alpha=5^{\circ}$.

Even with these differences, the predicted flow patterns match the PSP results fairly well, accurately representing the span-wise components of the flow associated with boundary layer separation in front of the nacelles and near the trailing edge of the flaperons between the nacelles. The predicted inward turning of the flow near the leading edge for the outermost row on the right is also confirmed by the wind tunnel data. In addition to the flow direction information, the PSP picture also reveals the location of the wing shock, running span-wise across the figure about 1 nacelle length ahead of the outboard nacelles. The shock is slightly ahead of the location predicted by CFD (blue-green line), which is consistent with the higher Reynolds number used in the computations.

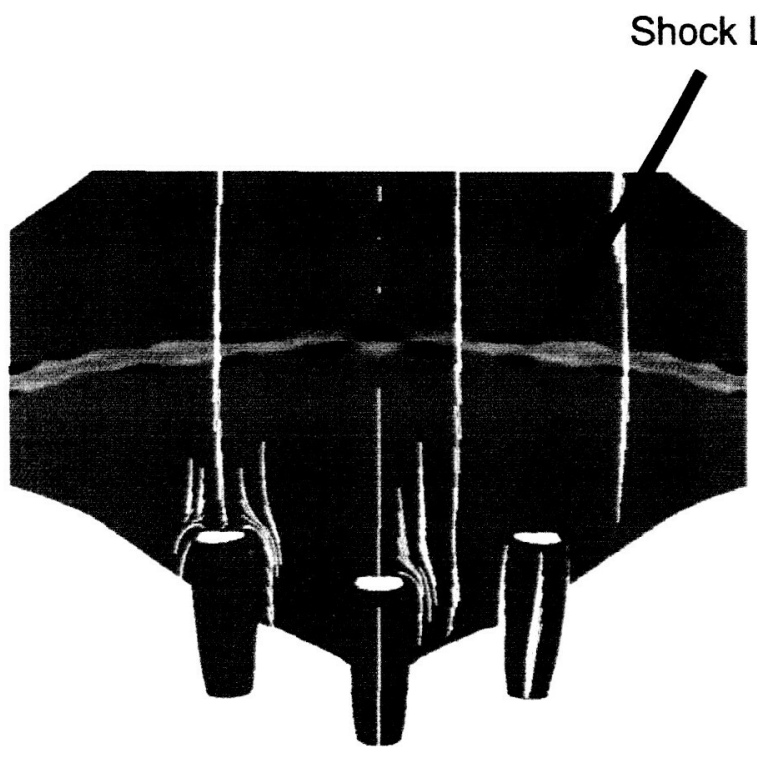

a),

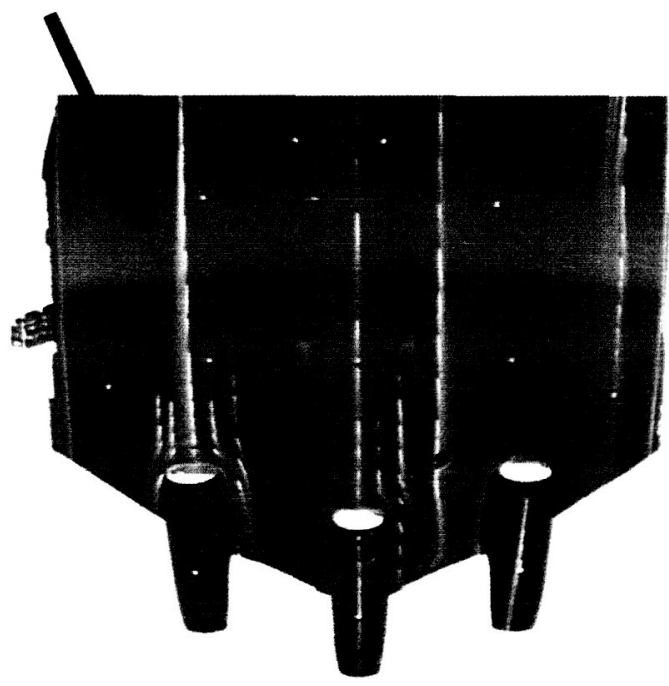

b),

Figure 11. Comparison of CFD solution with experimentally observed streamlines on the BWB model. a) CFD solution computed at $M=0.85, \alpha=4^{\circ}$, and Reynolds number of $75 \times 10^{6}$ (based on mean aerodynamic chord; b) experimentally observed streamlines at $M=0.85, \alpha=4^{\circ}$, and Reynolds number of $20 \times 10^{6}$. 


\section{Conclusions}

This work has demonstrated a viable approach to performing flow visualization on a surface using a modified PSP approach. A flow visualization technique that did not require seeding or introduction of any foreign components into the tunnel was required because of the pristine conditions needed to run at cryogenic conditions. To satisfy this, a BWB model was painted with a cryogenic PSP formulation and air was ejected through several dozen pressure port orifices already present on the model surface. Validation of this technique was accomplished using a small wind tunnel and purging pressure ports with nitrogen, showing that optimum purging pressure was several $\mathrm{kPa}(<50)$ above tunnel operating pressure. Further experimentation showed that this did not significantly change with tunnel operating speed.

Results on a BWB model at the NTF showed streamlines that were to be expected, including choking and even flow reversal near the nacelle inlets. Furthermore, this technique has demonstrated the ability to monitor shock locations by the slight changes in the refractive index over the model. At cryogenic conditions, it was determined that greater care in painting near model seams needs to be done to ensure that paint is not damaged or removed at cold temperatures. Even very small amounts of moisture can freeze in the purge air lines thereby blocking them. To prevent this, purge air should be provided only when the model is at test conditions. Also, care must be exercised to provide a uniform distribution of purge air to the pressure taps through appropriate manifold techniques. Finally, the results were compared with predictions and showed excellent agreement.

\section{Acknowledgments}

The authors would like to thank Mr. Edward Massey and Mr. Roger Bell for writing the data acquisition and analysis software, assisting in validating the PSP system, and acquiring data at the NTF. The authors would also like to thank the tunnel operators and support staff on the National Transonic Facility for their support during this test. Funding for this work was provided by NASA through the Ultra-Efficient Engine Technology Program (UEET) in the Vehicles System program.

\section{References}

${ }^{1}$ Kavandi, J., Callis, J., Gouterman, M., Khalil, G., Wright, D., Green, E., Burns, D., and McLachlan, B., "Luminescence Barometry in Wind Tunnels," Review of Scientific Instruments, Vol. 61, No. 11, 1990, pp. 3340-3347.

${ }^{2}$ Morris, M.J., Benne, M.E., Crites, R.C., and Donovan, J.F., "Aerodynamic Measurements Based in Photoluminescence," AIAA Paper 93-0175, $31^{\text {st }}$ Aerospace Sciences Meeting and Exhibit, Reno, Nevada, January 11-14, 1993.

${ }^{3}$ McLachlan, B. and Bell, J., "Pressure-Sensitive Paint in Aerodynamic Testing," Experimental Thermal and Fluid Science, Vol. 10, No. 4, pp. 470-485

${ }^{4}$ Torgerson, S., Liu, T., and Sullivan, J., "Use of Pressure Sensitive Paints in Low Speed Flows," AIAA Paper 96-2184, Advanced Measurement and Ground Testing Technology Conference, New Orleans, Louisiana, June 17-20, 1996.

${ }^{5}$ Coleman, P.B., Wallis, S.B., Dale, G.A., Jordan, J.D., Watkins, A.N., Goss, L., Davis, C.P.N., and Walter, T.M., "A Comparison of Pressure Sensitive Paint (PSP) Techniques for Aerodynamic Testing at Slow Velocities," Society of Automotive Engineers Paper 2002-01-255, SAE 2002 World Congress and Exhibition, Detroit, Michigan, March 2002.

${ }^{6}$ Jordan, J.D., Watkins, A.N., Davis, J., Weaver, W.L., Dale, G.A., Navarra, K., Urban, J., Devoid, W., and Stange, R., "Pressure-Sensitive Paint Measurements in a Large Scale Commercial Engine Test Stand," Proceedings of the $18^{\text {th }}$ International Congress on Instrumentation in Aerospace Simulation Facilities, Toulouse, France, June 14-17, 1999.

Carroll, B., Abbott, J. Lukas, E., and Morris, M., "Pressure Sensitive Paint Response to a Step Pressure Change," AIAA Paper 95-0483, 33 ${ }^{\text {rd }}$ Aerospace Sciences Meeting and Exhibit, Reno, Nevada, January 9-12, 1995.

${ }^{8}$ Winslow, N., Carroll, B., and Setzer, F., "Frequency Response of Pressure Sensitive Paints," AIAA Paper 96-1967, 27 Fluid Dynamics Conference, New Orleans, Louisiana, June 17-20, 1996.

${ }^{9}$ Liu, T., Campbell, B., Burns, S., and Sullivan, J., "Temperature- and Pressure-Sensitive Luminescent Paints in Aerodynamics," Applied Mechanics Review, Vol. 50, No. 4, 1997, pp. 227-246.

${ }^{10}$ Bell, J.H., Schairer, E.T., Hand, L.A., and Mehta, R.D., "Surface Pressure measurements Using Luminescent Coatings," Annu. Rev. Fluid Mech., Vol. 33, 2001, pp. 155-206.

${ }^{11}$ Liu, T., and Sullivan, J.P., "Pressure and Temperature Sensitive Paints (Experimental Fluid Dynamics)," Springer-Verlag, Berlin, 2004.

${ }^{12}$ Lackowicz, J., Principles of Fluorescence Spectroscopy, Second Edition, Plenum Press, New York, 1999, Chapter 8.

${ }^{13}$ Asai, K. Kanda, H., and Kunimasu, T., "Detection of Boundary-Layer Transition in a Cryogenic Wind Tunnel by Using Luminescent Paint," ALAA Paper 96-2185, Advanced Measurement and Ground Testing Technology Conference, New Orleans, Louisiana, June 17-20, 1996.

${ }^{14}$ Upchurch, B.T. and Oglesby, D.M., "New PSP Developments at NASA Langley Research Center - Low Temperature PSP," Proceeding of the $6^{\text {th }}$ Annual Pressure Sensitive Paint Workshop, Seattle, Washington, October 6-8, 1998, pp. 10-1 - 1024. 
${ }^{15}$ Asai, K., Amao, Y., Iijima, Y., Okura, I., and Nishide, H., "Novel Pressure-Sensitive Paint for Cryogenic and Unsteady Wind Tunnel Testing," AlAA Paper 2000-2527, $21^{\text {st }}$ AIAA Aerodynamic Measurement Technology and Ground Testing Conference, Denver, Colorado, June 19-22, 2000.

${ }^{16}$ Peterson, J.I. and Fitzgerald, R.V., "New Technique of Surface Flow Visualization Based on Oxygen Quenching of Fluorescence," Review of Scientific Instruments, Vol. 51, No. 5, 1980, pp. 670-671.

${ }^{17}$ Puklin, E., Carlson, B., Gouin, S., Costin, C., Green, E., Ponomarev, S., Tanji, H., and Gouterman, M., "Ideality of Pressure Sensitive Paint. I. Platinum Tetra(pentafluorophenyl)porphine in Fluoroacrylic Polymer," Journal of Applied Polymer Science, Vol. 77 , No. 13, 2000, pp. 2795-2804.

${ }^{18}$ Gouterman, M.P. and Carlson, W.B., University of Washington, Seattle, Washington, U.S. Patent for "Acrylic and Fluoroacrylic Polymers for Oxygen Pressure Sensing and Pressure-Sensitive Paints Utilizing these Polymers," Patent No. $5,965,642$, issued October 12, 1999.

${ }^{19}$ Masuda, T., Isobe, E., and Higashimura, T., "Poly[1-(trimethylsilyl)-1-propyne]: A New Polymer Synthesized With Transition-Metal Catalysts and Characterized By Extremely High Gas Permeability," Journal of the American Chemical Society, Vol. 105, No. 25, 1983, pp. 7473-7474.

${ }^{20}$ Bell, J.H., "Applications of Pressure-Sensitive Paint to Testing at Very Low Speeds," ALAA Paper 2004-0878, 42 ${ }^{\text {nd }}$ AIAA Aerospace Sciences Meeting and Exhibit, Reno, Nevada, January 5-8, 2004

${ }^{21}$ Hamner, M.P., Pompernack, Jr., T.G., Owens, L.R., and Wahls, R.A., "Using Temperature Sensitive Paint Technology," AIAA Paper 2002-0742, 40 ${ }^{\text {th }}$ AIAA Aerospace Sciences Meeting and Exhibit, Reno, Nevada, January 14-17, 2002.

${ }^{22}$ Campbell, R.L., Carter, M.B., Pendergraft, O.C., Jr., Friedman, D.M., and Serrano, L., "Design and Testing of a Blended Wing Body with Boundary Layer Ingestion Nacelles at High Reynolds Numbers," AIAA Paper 2005-0459, 43 ${ }^{\text {rd }}$ AIAA Aerospace Sciences Meeting and Exhibit, Reno, Nevada, January 10-13, 2005.

${ }^{23}$ Frink, N.T., "Assessment of an Unstructured-Grid Method for Predicting 3-D Turbulent Viscous Flows," ALAA Paper 1996-0292, 34 ${ }^{\text {th }}$ Aerospace Sciences Meeting and Exhibit, Reno, Nevada, January 15-18, 1996.

${ }^{24}$ Campbell, R.L., "Efficient Viscous Design of Realistic Aircraft Configurations," AIAA Paper 1998-2539, 29 $9^{\text {th }}$ Fluid Dynamics Conference, Albuquerque, New Mexico, June 15-18, 1998. 